\title{
Tratamento da Artrite Reumatóide (AR)
}

\section{Treatment for rheumatoid arthritis}

\author{
Seleção de artigos e comentários feitos por
}

Adriana Fontes Zimmermann ${ }^{(1)}$

Van Vallenhoven RF, Brannemark S, Klareskog L: Dose escalation of infliximab in clinical practice: improvements seen may be explained by a regression-like effect (Escalonamento das doses de infliximabe na prática clínica: melhoras podem ser explicadas por um efeito regressão-símile). Ann Rheum Dis 63:426-30, 2004. Instituição: Department of Rheumatology, Karolinska Hospital, Estocolmo, Suécia.

Um procedimento que vem sendo utilizado de forma crescente na prática clínica consiste em aumentar a dose infundida de infliximabe acima de $3 \mathrm{mg} / \mathrm{kg}$ (em geral, $5 \mathrm{a}$ $10 \mathrm{mg} / \mathrm{kg}$ ) nos pacientes com artrite reumatóide (AR) que não estejam apresentando resposta satisfatória. Para avaliar se há fundamento científico nesta conduta, os autores estudaram retrospectivamente 124 pacientes com AR tratados no Karolinska Hospital com agentes biológicos pertencentes ao banco de dados STURE (Stockholm TNF-alpha followup registry, com início em 1999). Os pacientes foram divididos em três grupos (um grupo de casos e dois grupos de controles), sendo 44 pacientes cujas doses de infliximabe foram aumentadas para $5 \mathrm{a} 7 \mathrm{mg} / \mathrm{kg}$ por infusão (casos), 44 pacientes com infliximabe sem aumento da dose (controles) e 36 pacientes tratados com etanercepte, com doses constantes de $40 \mathrm{mg}$ duas vezes por semana (controles). Todas as infusões de infliximabe foram realizadas a cada 8 semanas. Não havia diferença significante entre os grupos em termos de doses concomitantes de prednisona e de metotrexato (grupos do infliximabe) e as mesmas foram mantidas constantes durante o período de observação. Foram feitas as seguintes análises: No grupo de casos, comparou-se a atividade da doença pelo DAS28, SJC (swollen joint count, número de articulações edemaciadas) e ACR-N (índice porcentual de melhora do Colégio Americano de Reumatologia) na visita anterior à decisão de aumentar a dose (sendo a infusão com a nova dose aplicada dali a em média três semanas) com a primeira avaliação após o aumento da dose (pré-aumento da dose vs pós-aumento da dose, com intervalo de em média quatro meses). Foram comparados também os melhores índices dos escores alcançados pelos pacientes em qualquer tempo ("melhores resultados") antes e após o aumento da dose, utilizando-se também os critérios do EULAR. Para os controles, as análises utilizadas para comparação foram aquelas feitas no momento do primeiro aumento do DAS28 após o início do tratamento ("ponto de referência", que corresponde ao ponto de aumento da dose nos casos, ou de deterioração clínica), registrando-se da mesma forma do que nos casos as comparações entre os valores do ponto de referência com os "melhores resultados" alcançados pelos controles, de acordo com os mesmos escores e também os valores antes e depois do ponto de referência. Os resultados no grupo dos casos mostraram melhora significante do DAS28 na análise pré vs pós-aumento da dose, sendo que os "melhores resultados" deste escore foram alcançados após uma média de três infusões depois do aumento da dose. O número de articulações dolorosas (SJC) também apresentou redução significante nas mesmas análises. Os "melhores resultados" de ambos os escores, assim como do ACR-N antes e depois do aumento da dose foram similares. De modo geral, o índice de melhora dos escores foi quantitativamente modesto (por exemplo, apenas 36\% dos pacientes alcançaram resposta de boa a moderada pelos critérios do EULAR). A comparação com os controles revelou que os valores do DAS28 foram muito semelhantes nos três grupos. O tempo decorrido do ponto de referência até os "melhores resultados" foi de em média 10,3 meses para os do

\footnotetext{
1. Serviço de Reumatologia do Hospital Universitário da Universidade Federal de Santa Catarina, Florianópolis-SC, Brasil.
} 
etanercepte e 7,2 meses para os controles do infliximabe (idem aos casos). Os padrões do SJC e ACR-N mostraram-se também muito similares nos três grupos. A discussão enfatiza que a melhora dos pacientes com AR em uso do infliximabe após aumento da dose, apesar de poder ser interpretada como a "recaptura" do efeito benéfico, pode também ser explicada por um efeito regressão-símile, visto que o padrão de melhora dos escores parece ocorrer também nos pacientes com dose inalterada e naqueles em uso de etanercepte, podendo refletir o comportamento próprio da doença reumatóide. Os autores alertam para o grande aumento dos custos que maiores doses de infliximabe acarretam, assim como o aumento potencial do número e gravidade dos efeitos colaterais. Recomendam ainda aos médicos que, ao adotar tal conduta, atenham-se a protocolos pré-definidos de acompanhamento destes pacientes.

Van Vollenhoven R, Harju A, Brannemark S, Klareskog L: Treatment with infliximab (Remicade) when etanercept (Enbrel) has failed or vice versa: data from the STURE registry showing that switching tumor necrosis factor alpha blockers can make sense (Tratamento com infliximabe (Remicade) quando etanercepte (Enbrel) falhou ou vice versa: dados do registro STURE mostrando que trocar o bloqueador do TNF-alfa pode fazer sentido). Ann Rheum Dis 62:1195-8, 2003. Department of Rheumatology, Karolinska Hospital, Estocolmo, Suécia.

Neste estudo, também retrospectivo observacional, os autores selecionaram 31 pacientes com seguimento registrado no banco de dados STURE (v. acima) que receberam ambos os bloqueadores do TNF infliximabe e etanercepte. Dezoito foram primeiramente tratados com etanercepte (doses subcutâneas de $25 \mathrm{mg}$ duas vezes por semana) e depois com infliximabe (infusões intravenosas de $3 \mathrm{mg} / \mathrm{kg}$ a intervalos de $0,2,6$ e 8 semanas a partir de então) e 13 pacientes receberam estes agentes em ordem inversa. Foram analisados os melhores resultados obtidos com cada uma das drogas em cada paciente (melhores DAS28, SJC e ACR-N; v. acima), assim como o número de pacientes que responderam com índice ACR20. Além disso, foram comparados também os valores para estas variáveis imediatamente antes de iniciar cada tratamento e à época de sua suspensão. Dos 18 pacientes tratados primeiramente com etanercepte $(14$ com AR, 2 com AIJ já adultos e 2 com espondiloartropatia), 14 mudaram para infliximabe por falta de eficácia, 2 por efeitos adversos relacionados com a droga (rinorréia e congestão nasal) e 2 em razão de causa desconhecida, tendo usado etanercepte por em média 6,8 meses. Onze dos 18 pacientes vinham usando metotrexato (MTX) juntamente com etanercepte, que foi mantido em todos os casos quando trocado para infliximabe. Além disso, nesta ocasião MTX foi iniciado em outros 4 pacientes e os 3 restantes não receberam MTX em nenhum momento do tratamento com bloqueadores do TNF. Após a troca para infliximabe, o melhor DAS28 foi significantemente menor do que logo antes da mudança $(p<0,02)$, assim como com relação ao melhor DAS28 durante o tratamento com etanercepte $(\mathrm{p}<0,05)$. O índice ACR-N foi também melhor após o início do infliximabe, porém a diferença não alcançou significância estatística, além de observar-se maior proporção de pacientes que atingiram ACR20 em comparação ao tratamento com etanercepte (67\% vs $33 \%)$. As respostas favoráveis foram mantidas, conforme acompanhamento destes pacientes por até 24 meses. Dos 13 pacientes que primeiramente receberam infliximabe, a razão para a troca por etanercepte foi a ocorrência de eventos adversos em 11 ( 7 reações infusionais, 2 toxicidade hepática, 1 alteração no olfato e 1 não especificada) e razões várias em 2 pacientes. Todos os pacientes receberam MTX associado ao infliximabe e o tempo médio de tratamento com este agente foi de 5,5 meses. Quando houve a troca para etanercepte, MTX foi mantido em 8 e descontinuado em 5 pacientes. Com relação ao DAS28, ocorreu resposta significante com infliximabe, porém à época de início do etanercepte os valores deste escore haviam piorado, mantendo-se ainda significantemente menores do que no início do tratamento com infliximabe. No entanto, quando o etanercepte foi iniciado, observou-se melhora importante no DAS28, significantemente menor do que o melhor resultado com infliximabe. O número de articulações edemaciadas (SJC) também sofreu redução, porém de magnitude não significante em comparação com o melhor índice visto com infliximabe. O ACR-N foi virtualmente idêntico para os dois agentes e o número de respostas ACR20 foi também similar. Bons resultados também foram mantidos ao longo de 24 meses de acompanhamento adicional. Os resultados apresentados sugerem que, para aqueles pacientes nos quais os resultados clínicos com etanercepte associado ou não a MTX foram inadequados, a troca para infliximabe mais 
MTX pode trazer melhora considerável. Da mesma forma, em pacientes que apresentem efeitos adversos ao infliximabe, o tratamento com etanercepte parece ser capaz de fornecer bons resultados. Entretanto, os autores ressaltam que o pequeno número de pacientes incluído no estudo e as diferenças entre os grupos (razões para a troca do agente anti-TNF, outros diagnósticos que não $\mathrm{AR}$, diferenças no uso de MTX), não permitindo comparações diretas entre os grupo, implicam em que os resultados devam ser analisados com cautela. Além disso, reiteram a recomendação de registros sistemáticos de acompanhamento dos pacientes em uso de bloqueadores do TNF, a fim de obter respostas concluentes para a questão da troca de drogas, considerando seu elevado custo e os riscos inerentes à sua utilização.

Genovese MC, Cohen S, Moreland L, et al: Combination therapy with etanercept and anakinra in the treatment of patients with rheumatoid arthritis who have been treated unsuccessfully with methotrexate (Terapia de combinação com etanercepte e anakinra no tratamento de pacientes que foram tratados sem sucesso com metotrexato). Arthritis Rheum 50:1412-9, 2004. The 20000223 Study Group. Stanford University, Palo Alto, CA, EUA.

Para testar a hipótese, sugerida por estudos prévios em modelos animais, de que a associação de anakinra e etanercepte resultaria em efeitos terapêuticos sinérgicos, especialmente quando administrados em doses sub-ótimas de cada agente, realizou-se o presente estudo multicêntrico, randomizado e placebo-controlado. Foram incluídos 242 pacientes com artrite reumatóide ativa (maioria mulheres, com doença muito ativa e de longa duração) que vinham recebendo doses de metotrexato $(10-25 \mathrm{mg} / \mathrm{semana})$ há pelo menos 16 semanas, estáveis há pelo menos 8 semanas e que nunca tivessem recebido quaisquer agentes biológicos. Oitenta e um pacientes receberam $25 \mathrm{mg}$ de etanercepte bi-semanalmente mais anakinra placebo, 81 pacientes receberam etanercepte $25 \mathrm{mg}$ uma vez por semana (mais uma dose semanal de etanercepte placebo) mais $100 \mathrm{mg}$ diários de anakinra e os 81 restantes receberam $25 \mathrm{mg}$ de etanercepte duas vezes por semana mais anakinra $100 \mathrm{mg}$. Todas as drogas foram administradas por via subcutânea, por um período de 24 semanas. Os pacientes continuaram utilizando as mesmas doses de metotrexato e corticosteróides durante todo o estudo, sendo as avaliações efetuadas nas semanas 0 (basal), 2, 4, 8, 16, 20 e 24, com uma avaliação final quatro semanas após o término da medicação (semana 28). As avaliações incluíam: registro de eventos adversos; testes laboratoriais; medidas de atividade da doença do ACR; DAS (Disease Activity Score) modificado; critérios de resposta do EULAR; duração da rigidez matinal. Foi também preenchido o questionário de saúde SF-36 (Short Form) nas semanas $0,4,12$ e 24 ou na ocasião de saída do paciente do estudo, quando esta acontecia precocemente. O objetivo primário foi a proporção de pacientes que atingiram resposta ACR50 na semana 24. Foram medidas as concentrações séricas de etanercepte e anakinra nas semanas $0,4,12$ e 24 (ou por ocasião da saída) e de anticorpos contra estas drogas nas semanas 0, 12 e 24 (ou na saída). No grupo do etanercepte isolado, 93\% dos pacientes completaram o estudo e nenhum paciente foi retirado em razão de efeitos colaterais, enquanto no grupo de meia dose de etanercepte mais ankinra e de dose plena de etanercepte mais anakinra, $78 \%$ e $80 \%$ dos pacientes completaram o estudo, sendo que 7 e 6 pacientes, respectivamente, saíram por efeitos colaterais (análise estatística mostrou que isto não influenciou os resultados). O tratamento com etanercepte isolado resultou em obtenção do ACR50 em 41\% dos pacientes, comparado com 31\% no grupo de dose plena de etanercepte mais anakinra (não significante). A única comparação de eficácia estatisticamente significante foi que na semana 24 a proporção de pacientes com ACR20 foi superior no grupo do etanercepte isolado em comparação com o grupo meia dose de etanercepte mais anakinra. A maioria dos pacientes em todos os grupos atingiu índice de resposta do EULAR bom a moderado (79\% para etanercepte isolado, $73 \%$ dose plena de etanercepte+anakinra e $66 \%$ meia dose de etanercepte+anakinra). As dosagens séricas das drogas demonstraram que a farmacocinética de um agente pareceu não ser afetada pela administração do outro. O índice global de eventos adversos foi similar em todos os grupos $(90 \%$ a 95\%), mas os grupos de combinação apresentaram maior proporção de eventos adversos sérios, eventos que causaram a retirada do estudo e reações no local das injeções (mais de 50\% mais freqüentes, em geral transitórias e não severas, porém foram a causa mais freqüente de saída do estudo). Infecções sérias, não relacionadas com neutropenia, foram observadas em 9 de 16 pacientes com neutropenia, ocorrendo em média dois meses após o início do tratamento 
combinado, sendo que um paciente morreu de pneumonia. Três pacientes desenvolveram anticorpos anti-anakinra, porém sem relação aparente com eficácia ou eventos adversos. Os autores discutem as possíveis causas de discrepância entre os resultados do presente estudo e os estudos pré-clínicos, sugerindo que isto se deva ao papel das citocinas IL-1 e TNF e suas complexas interações na doença reumatóide humana, devendo ser melhor esclarecido em investigações de ciência básica. A conclusão dos pesquisadores é de que os resultados deste estudo, mostrando que a associação de etanercepte e anakinra não apresenta eficácia clínica superior ao etanercepte isoladamente e predispõe à maior incidência de infecções sérias, sugerem que o uso de tal combinação não deve ser recomendado em pacientes com AR.

Edwards JCW, Szczepanski L, Szechinski J, et al: Efficacy ob B-cell-targeted therapy with rituximab in patients with rheumatoid arthritis (Eficácia da terapia contra células B rituximabe em pacientes com artrite reumatóide). N Engl J Med 350:2572-81, 2004. Centre for Rheumatology,University College London, Londres, UK.

Conforme sugerido por um estudo aberto anterior, neste estudo randomizado, duplo-cego e placebo-controlado com 24 semanas de duração testou-se a eficácia do rituximabe, isoladamente ou em combinação com ciclofosfamida ou metotrexato (MTX) no tratamento da artrite reumatóide (AR) ativa a despeito do uso de metotrexato. Foram incluídos 161 pacientes, provenientes de 11 países (8 países europeus, Israel, Austrália e Canadá), a maioria mulheres com doença soropositiva de longa duração e que vinham utilizando pelo menos $10 \mathrm{mg} / \mathrm{semana}$ de metotrexato como único DMARD por um período mínimo de 16 semanas, com dose estável há pelo menos 4 semanas. Quatro grupos de tratamento foram formados: metotrexato oral (mínimo $10 \mathrm{mg} / \mathrm{semana}$ ), rituximabe, rituximabe mais ciclofosfamida e rituximabe mais metotrexato. O rituximabe foi administrado em uma dose intravenosa de 1000mg nos dias 1 e 15 e a ciclofosfamida na dose intravenosa de $750 \mathrm{mg}$ nos dias 3 e 17. Todos os pacientes, inclusive no grupo controle, receberam um curso de corticosteróides por 17 dias, consistindo de infusões endovenosas de 100mg de metilprednisolona antes das infusões do rituximabe, ciclofosfamida ou placebo, associadas a $60 \mathrm{mg} /$ dia de prednisona oral dos dias 2 a 7 e 30mg/dia dos dias 8 a 14, além de ácido folínico em dose única oral de $10 \mathrm{mg}$ no dia 1 . As avaliações clínicas foram realizadas no dia 1 e nas semanas 12, 16, 20 e 24, de acordo com os critérios do ACR de atividade da doença e de resposta do EULAR; as avaliações laboratoriais (hemograma completo e bioquímica) foram feitas no "screening" (3 semanas antes do dia 1), dias 1, 3, 15, 17 e semanas 4, 8, 12, 16, 20 e 24. Foram também dosados níveis séricos de células B-CD19+ e células T CD3+, CD4+ e $\mathrm{CD} 8+$, concentração de imunoglobulinas (IgA, IgG e IgM) e fator reumatóide, além dos títulos de anticorpos antitetânicos, a fim de investigar a imunidade adquirida.
Foram realizadas avaliações clínico-laboratoriais adicionais a intervalos regulares até 48 semanas, mantendo-se o cegamento. Os resultados mostraram que na semana 24 , com relação ao objetivo primário do estudo (proporção de pacientes que atingiram ACR50), os regimes de combinação de rituximabe com ciclofosfamida ou com MTX foram superiores ao grupo controle de metotrexato isolado $(\mathrm{p}=0,005)$ e ao grupo de rituximabe isolado $(\mathrm{p}=0,059)$. Quanto ao objetivo secundário (ACR20 e ACR70), houve maior proporção de pacientes nos grupos do rituximabe (ACR20 significante em todos os grupos de rituximabe e ACR70 no grupo rituximabe-MTX) em comparação com o grupo controle. Na semana 24, um número significantemente maior de pacientes nos grupos com rituximabe apresentou melhora nos índices de atividade da doença (ACR) com relação aos controles $(p<0,002)$, assim como resposta ao tratamento ( $\mathrm{p}<0,004$, critérios do EULAR). $\mathrm{Na}$ semana 48, a proporção de pacientes com ACR70, ACR 50 e ACR 20 foi de $0 \%, 5 \%$ e $20 \%$ respectivamente no grupo controle, contra $15 \%, 30 \%$ e $65 \%(p=0,03, p=0,002$ e $\mathrm{p}<0,001)$, respectivamente no grupo rituximabe-MTX e $10 \%$ (não significante), $27 \%$ e $49 \%(\mathrm{p}=0,01$ para ambos) no grupo rituximabe-ciclofosfamida. Nas 24 primeiras semanas todos os grupos apresentaram incidência global similar de eventos adversos (73\% a 85\%), sendo que 30\% a $45 \%$ dos pacientes em cada grupo tiveram reações à primeira infusão, a maioria (85\% a 90\%) caracterizada como leve a moderada (hipotensão ou hipertensão, tosse, prurido e rash). Dezesseis eventos adversos sérios foram relatados em 14 pacientes, mais freqüentemente no grupo rituximabeciclofosfamida. Infecções sérias ocorreram em um paciente $(2,5 \%)$ no grupo controle e em 4 pacientes $(3,3 \%)$ nos grupos do rituximabe (2 no grupo rituximabe isolado, um dos quais com doença cardíaca concomitante evoluiu para 
óbito por broncopneumonia sem agente etiológico definido e 2 no grupo rituximabe-ciclofosfamida). Durante as 48 semanas de acompanhamento ocorreram mais 6 eventos adversos sérios, incluindo duas infecções (uma com rituximabe isolado e uma com rituximabe-MTX). O uso de rituximabe levou a uma completa depleção das células B periféricas durante as 24 semanas, porém as imunoglobulinas se mantiveram em níveis normais e não houve alteração nos títulos de anticorpos antitetânicos, sendo que os níveis de fator reumatóide sofreram uma grande e rápida redução, sustentada na semana 24. Em todos os pacientes as células $T$ inicialmente sofreram redução e depois voltaram a aumentar seus níveis, efeito provavelmente relacionado com o uso inicial de corticosteróides. Os autores discutem os possíveis mecanismos de participação das células $\mathrm{B}$ na patogênese da artrite reumatóide, considerando que o uso do rituximabe teve efeito benéfico sobre as respostas dos índices do ACR, sustentado até 48 semanas após o curso de tratamento. Quanto ao perfil de segurança, comentam que os eventos adversos nos pacientes com AR são mais freqüentes na primeira infusão, porém parecem ter menor incidência e severidade do que nos pacientes com linfoma, por causas desconhecidas. Apesar da depleção das células B causada pelo rituximabe, a ocorrência global de infecções nos grupos em uso deste agente foi interpretada pelos autores como similar à do grupo controle nas 24 e 48 semanas, porém observa-se que dentro das 48 semanas de acompanhamento ocorreram mais dois casos de infecções sérias, sendo um de evolução fatal, o que alerta para a necessidade de rigoroso controle de segurança em futuros estudos.

Kremer JM, Habros JS, Kolba KS, et al: Tacrolimus in rheumatoid arthritis patients receiving concomitant methotrexate. A six-month, open-label study (Tacrolimus em pacientes com artrite reumatóide recebendo metotrexato concomitante. Um estudo aberto de 6 meses). Arthritis Rheum 48:2763-8, 2003. Albany, New York, EUA.

Com o objetivo de avaliar a segurança do uso combinado de metotrexato e tacrolimus, os autores realizaram um estudo aberto multicêntrico conduzido em 13 centros nos Estados Unidos em 80 pacientes portadores de artrite reumatóide ativa, apesar do uso de metotrexato (dose média $15 \mathrm{mg} /$ semana). Os pacientes receberam $3 \mathrm{mg}$ de tacrolimus via oral $1 \mathrm{vez}$ ao dia durante 6 meses, mantendo o uso prévio do metotrexato. Foram mantidas as mesmas doses de antiinflamatórios não hormonais e corticosteróide oral (menor ou igual a $10 \mathrm{mg}$ de prednisona). Sessenta e três pacientes completaram o estudo $(78,8 \%)$ e o ACR 20 foi o critério de resposta clínica principal a ser avaliada. Sete pacientes $(12,5 \%)$ saíram do estudo em razão da presença de efeitos adversos possivelmente ou provavelmente relacionados com o trata- mento com tacrolimus. Quatro pacientes saíram do estudo por falta de eficácia do tratamento. Um dos pacientes desenvolveu pancreatite, a qual foi possivelmente relacionada com o uso do tacrolimus. Os níveis de creatinina aumentaram discretamente de $0,74 \mathrm{mg} / \mathrm{dl}+/-0,16$ para $0,81+/-0,22 \mathrm{mg} /$ $\mathrm{dl}(\mathrm{p}<0,001)$. Vinte e três pacientes $(28,8 \%)$ tiveram um aumento maior que $30 \%$ nos níveis de creatinina basal, com níveis acima do normal em três destes pacientes. $\mathrm{O}$ nível máximo de creatinina durante o estudo foi de $1,8 \mathrm{mg} / \mathrm{dl}$. A resposta ACR 20 ao fim do estudo foi de 52,5\%. Os autores assim discutem que o uso de tacrolimus em combinação com o metotrexato é seguro naqueles pacientes com artrite reumatóide ativa apesar do uso de metotrexato, e determina melhora clínica.

Kremer JM, Westhovens R, Leon M, et al: Treatment of rheumatoid arthritis by selective inhibition of T-Cell activation with fusion protein CTLA4Ig (Tratamento da artrite reumatóide pela inibição seletiva da ativação da célula T com proteína de fusão CTLA4Ig). N Engl J Med 349:1907-15, 2003. Albany, New York, EUA.

Considerando que assim como as citocinas derivadas dos macrófagos, os linfócitos $\mathrm{T}$ são também alvos importantes para ação das novas terapias em pacientes com artrite reumatóide, os autores realizaram um estudo com CTLA4Ig. A CTLA4Ig é uma proteína de fusão que bloqueia a coestimulação entre as células apresentadoras de antígeno e os linfócitos T. A CTLA4Ig liga-se às moléculas CD80 e CD86 nas células apresentadoras de antígenos, bloqueando a ligação destas às moléculas de superfície CD28 nas células $\mathrm{T}$, impedindo assim a sua ativação. Os autores randomizaram 105 pacientes com AR ativa apesar do uso de metotrexato para receber $2 \mathrm{mg} / \mathrm{kg}$ de CTLA4Ig, 115 para receber 
$10 \mathrm{mg} / \mathrm{kg}$ e 119 pacientes para receber placebo durante 6 meses. Todos os pacientes mantiveram o uso do metotrexato. Após 6 meses $60 \%$ dos pacientes que receberam $10 \mathrm{mg} / \mathrm{kg}$ de CTLA $4 \mathrm{Ig}$ alcançaram ACR 20 vs $35 \%$ com placebo $(\mathrm{p}<0,001)$. As diferenças com relação à ACR $50 \mathrm{e}$ à ACR 70 foram significantemente maiores em ambos os grupos com CTLA4Ig, com relação ao grupo placebo. O grupo que recebeu $10 \mathrm{mg} / \mathrm{kg}$ de CTLA4Ig teve melhora significante e estatisticamente diferente com relação ao questionário SF-36. A CTLA4Ig foi bem tolerada, com um perfil de segurança similar àquele dos pacientes com placebo. Os autores concluem que a CTLA4Ig melhorou significantemente os sinais e sintomas de artrite reumatóide e a qualidade de vida relacionada com a saúde. A CTLA4Ig permanece assim como uma terapia nova e efetiva nos pacientes com artrite reumatóide. 